\title{
Helicobacter Pylori Caga Status and Gastric
} Mucosa-Associated Lymphoid Tissue Lymphoma: A Systematic Review and Meta-Analysis

\section{Masoud Keikha}

Mashhad University of Medical Sciences

\section{Amirhossein Sahebkar}

Mashhad University of Medical Sciences

\section{Yoshio Yamaoka}

Oita University: Oita Daigaku

Mohsen Karbalaei ( $\nabla$ mohsen.karbalaei@jmu.ac.ir)

Jiroft University of Medical Sciences https://orcid.org/0000-0001-9899-2885

Research article

Keywords: Helicobacter pylori, Gastric MALT lymphoma, CagA antigen, Meta-analysis

Posted Date: October 1st, 2021

DOI: https://doi.org/10.21203/rs.3.rs-289927/v2

License: (c) (i) This work is licensed under a Creative Commons Attribution 4.0 International License.

Read Full License

Version of Record: A version of this preprint was published at Journal of Health, Population and Nutrition on January 3rd, 2022. See the published version at https://doi.org/10.1186/s41043-021-00280-9. 


\section{Abstract \\ Background}

Recent studies have investigated the role of Helicobacter pylori infection in the development of gastric mucosa-associated lymphoid tissue (MALT) lymphoma. It is estimated that approximately $0.1 \%$ of people infected with $H$. pylori develop gastric MALT lymphoma. However, the role of the CagA antigen, the highest causative agent of $H$. pylori, in increasing the risk of gastric MALT lymphoma remains unclear and controversial. A systematic review and meta-analysis were conducted to evaluate the effect of cag $A$ status on the development of gastric MALT lymphoma.

\section{Methods}

All articles evaluating the status of the cagA gene in the development of gastric MALT lymphoma were collected using systematic searches in online databases, including PubMed, Scopus, Embase, and Google Scholar, regardless of publication date. The association between cagA and gastric MALT lymphoma was assessed using the odds ratio (OR) summary. In addition, a random-effects model was used in cases with significant heterogeneity.

\section{Results}

A total of 10 studies met our inclusion criteria, among which 1,860 patients participated. No association between cagA status and the development of MALT lymphoma (extranodal marginal zone B-cell lymphoma) was found in this study (OR: 1.30; 0.906-1.866 with 95\% Cls; $P^{2}$ : 45.83; Q-Value: 12.92). Surprisingly, a meaningful association was observed between cagA status and diffuse large B-cell lymphoma (OR: $6.43 ; 2.45-16.84$ with $95 \% \mathrm{Cls}$ ). We also observed an inverse association between vacA and gastric MALT lymphoma risk (OR: 0.92; 0.57-1.50 with $95 \% \mathrm{Cls}$ ).

\section{Conclusions}

It seems that the infection with cagA-positive $H$. pylori strains does not have a meaningful effect on the gastric MALT lymphoma formation, while translocated CagA antigen into the $B$ cells plays a crucial role in the development of diffuse large B-cell lymphoma.

\section{Background}

Helicobacter pylori (H. pylori) is one of the most unique human pathogenic bacteria, and because of its exceptional ability to tolerate harsh stomach conditions, it colonizes the stomachs of about 4-4.5 billion people worldwide [1, 2]. Depending on environmental, socioeconomic, and health conditions, the prevalence of $H$. pylori infection varies in different geographical areas, with values of about $34 \%$ in 
Western countries and close to $100 \%$ in developing countries [3, 4]. Bacterial strains enter the gastric submucosa and cause chronic gastritis by evading the immune system response. However, $15-20 \%$ of people infected with $H$. pylori experience severe clinical outcomes, especially peptic ulcer disease (gastric ulcer or duodenal ulcer), chronic atrophy gastritis, and gastric adenocarcinoma, e.g., gastric cancer or mucosa-associated lymphoid tissue (MALT) lymphoma $[3,5,6]$.

It is currently unknown why most people infected with $H$. pylori are asymptomatic carriers, and severe clinical outcomes are seen only in a small part of the human population. The genomic content of $H$. pylori is specific to the strain, and evaluating the role of strain virulence factors is critical $[7,8]$. The cytotoxin-associated gene A (CagA) is one of the major virulence factors in this bacterium, which is encoded by the cag pathogenicity islands (PAls) and is classified into four different classes based on the flanking nucleotide sequence of EPIYA motifs [9]. The cagA pattern in the East Asian population is usually $A B D$, while strains containing patterns such as $A B C, A B C C$, and $A B C C C$ are isolated from Western countries $[10,11]$. According to previous studies, cagA-positive strains are significantly present in the population with gastric ulcers and precancerous lesions [12]. Although the role of CagA protein in tumorigenesis remains unclear, according to the first hypothesis, phosphorylated CagA can phosphorylate intracellular eukaryotic proteins, particularly SHP-2 and Src kinase, and induce the hummingbird phenotype and oncogenesis by altering the normal cell signaling pathway [13]. The affinity of EPIYA-D for the binding and effect of SHP2 tyrosine phosphatase is much higher than that of EPIYA-C, so the differences are reported to be related to the fact that the prevalence of gastric cancer in East Asia is higher than that in Western countries $[12,14]$.

According to the second hypothesis, CagA is an immunogenic protein that stimulates the production of interleukin 8 (IL-8) and leads to the infiltration of neutrophils in the inflamed area, the production of free radicals, and DNA damage [15-18]. Accordingly, infection with this bacterium appears to increase the risk of two cancers of the digestive system, including gastric cancer and gastric MALT lymphoma [19].

According to a new classification by World Health Organization (WHO), primary gastric lymphoma (PGL) can range from extranodal marginal zone B-cell lymphoma (MALT lymphoma) to diffuse large B-cell lymphoma (DLBCL) [20]. Gastric MALT lymphoma was first identified by Isaacson and Wright in 1983 and accounts for more than $50 \%$ of gastric lymphoma, a B-cell lymphoma derived from MALT during chronic inflammation $[19,21]$. Carlson et al. (1996) showed that $H$. pylori gastritis can lead to gastric MALT lymphoma by causing polyclonal lymphatic hyperplasia [22]. Although previous experiments suggested that gastric MALT lymphoma was primarily associated with $H$. pylori infection, recent studies have shown a much higher rate of gastric MALT lymphoma in H. pylori-negative patients [23]. In a study by Asenjo et al., the global prevalence of $H$. pylori infection in DLBCL and extranodal marginal zone B-cell lymphoma was estimated to be about $60 \%$ and $79 \%$, respectively [24]. Interestingly, the eradication of $H$. pylori infection is very effective in the regression of gastric MALT lymphoma; therefore, antibiotic therapy is considered the first line of treatment for gastric MALT lymphoma [25]. According to in vitro experiments, the immune response in extranodal marginal zone B-cell lymphoma is formed as a result of T cell-mediated immunity (CMI) $[26,27]$. Studies have shown that the CagA antigen can be translocated 
to B-cell lymphocytes following the destruction of gastric mucosa during chronic gastritis [28, 29]. In B cells, this antigen prevents apoptosis through extracellular signal-regulated kinase, which in turn leads to the proliferation and immortalization of B cells and eventually MALT lymphoma [29-31].

In general, despite limited information and conflicting results in some studies, events such as chronic inflammation, production of reactive oxygen species (ROS), B-cell proliferation, and genetic instability can lead to susceptibility to gastric MALT lymphoma [32-34]. In the present meta-analysis, we investigated the association between CagA antigen and MALT to evaluate the role of CagA in the development of gastric MALT lymphoma.

\section{Methods}

\subsection{Literature search}

We conducted a comprehensive electronic search using the following online databases: PubMed, Scopus, Embase, and Google Scholar to retrieve all relevant documents printed in English up until December 2020. The search for terms was performed based on the MeSH library [35]. Accordingly, we used words such as "Helicobacter pylori," "H. pylori," "MALT," "mucosa-associated lymphoid tissue," "CagA," "cagA gene", and "cytotoxin-associated gene A". The literature search was performed independently by two authors (MK1 and MK2) without publication date restrictions.

\subsection{Study selection}

In the first stage, after initial evaluations, duplicate articles were excluded from the study, and then a reference list of each article was evaluated to avoid losing additional documents. The inclusion criteria were as follows: 1) all original, cross-sectional, case-control, and longitudinal articles related to our purpose, 2) studies on the association between cagA gene status and gastric MALT lymphoma, 3) studies based on standard diagnostic methods such as polymerase chain reaction (PCR), ELISA, and conventional microbiology tests, and 4) studies published in English. Exclusion criteria were as follows: (i) congress abstracts, case series, review articles, and letters to the editor, II) articles without full text available, III) articles published in non-English language, IV) animal studies or in vitro studies, and V) studies with vague results and insufficient data.

\subsection{Quality assessment and data extraction}

The Newcastle-Ottawa Scale (NOS) checklist was used to assess the quality of the studies (Table 1). The required data, including the first author, country, population sample size, number of $H$. pylori strains, diagnostic method, and frequency of cagA-positive strains, are listed in Table 2. All participants were divided into case (gastric MALT lymphoma) and control (gastritis or non-ulcer dyspepsia) groups. 


\subsection{Statistical analysis}

All statistical analyses were performed using Comprehensive Meta-Analysis software (Ver 2.2, Biostat, Englewood, $\mathrm{NJ}$ ). The colonization rate of cagA-positive strains in both groups was reported as event rate (EER) with $95 \%$ confidence intervals (Cls). The impact of cagA gene status on the development of gastric MALT lymphoma was also measured using the odds ratio (OR) at $95 \% \mathrm{Cls}$. The heterogeneity between studies was assessed with the $P^{2}>50$ test and Cochran's Q Statistic $p$ value $>0.05$. High levels of heterogeneity were evaluated according to the random-effects model with the DerSimonian and Laird method. In contrast, the fixed-effects model, based on the Mantel-Haenszel method, was used for low levels of heterogeneity. Furthermore, publication bias was assessed using asymmetry of funnel plots, Begg's test $p$ value, and Egger's test $p$ value.

\section{Results}

\subsection{Characteristics of selected studies}

A total of 153 articles were collected in the initial search, and finally 10 eligible articles met our criteria and were included in the current analysis [36-45]. A flowchart of the article search strategy and study selection is presented in Fig. 1.

All eligible studies were conducted from 1996-2016, and data from 1860 patients were reviewed in these studies. Two studies were performed on the Asian population, and eight studies were conducted in Western countries. No significant relationship was observed between cagA status and age/sex distribution in any of the studies. In two studies, the association between the cagA genotype and the development of gastric MALT lymphoma was controversial [37, 44]. Unfortunately, the association between CagA EPIYA motifs and gastric MALT lymphoma had not been evaluated in all studies, so we could not investigate this association. However, in three studies, the association between cagA status and both extranodal marginal zone B-cell lymphoma and DLBCL forms of the MALT was investigated [37, 40, 41]. In addition, the association between vacA status and gastric MALT Iymphoma had been assessed in six studies [37-40, 43, 45].

\subsection{Association between cagA status and susceptibility to gastric MALT lymphoma}

In this study, patients were divided into cases (gastric MALT lymphoma: 280 patients) and control (gastritis/non-ulcer dyspepsia (NUD): 414 patients). The prevalence of CagA-expressing strains in patients with MALT lymphoma and gastritis/NUD patients was estimated to be $54.6 \%$ (44-64.7 with 95\% Cls) and $56.4 \%$ (41.5-70.3 with $95 \% \mathrm{Cls})$, respectively. However, according to the subgroup analysis by different geographical regions, we found that the frequency of cagA-positive strains in patients with gastritis/NUD in Western countries was higher than that in Asian countries ( $57.6 \%$ vs. $36.5 \%)$. The results 
showed that the $\operatorname{cag} A$ genotype was not significantly different between Western and Asian patients with gastric MALT lymphoma.

Based on the results of statistical analysis, no association was observed between cagA status and gastric MALT lymphoma (OR: $1.00 ; 0.715-1.419$ with $95 \%$ Cls; $p$ value: $0.968 ; ~ P: ~ 83.52 ;$ Q-Value: $54.61 ; p$ value: 0.01 ; Egger's $p$ value: 0.36 ; Begg's $p$ value: 0.28 ) following long-term $H$. pylori infection (Fig. 2).

In the subgrouping, we found that there was an inverse association between cagA genotype and gastric MALT lymphoma in the Asian population (OR: 0.104; 0.036-0.307 with 95\% Cls; P: 95.6; Q-Value: 23.08; $p$ value: 0.08 ), while there was no meaningful association between cagA-positive strains and the development of gastric MALT lymphoma in Western countries (OR: $1.30 ; 0.906-1.866$ with $95 \%$ Cls; $P$ : 45.83; Q-Value: $12.92 ; p$ value: 0.58 ). According to the results of statistical analysis (OR: $6.43 ; 2.45-16.84$ with $95 \%$ Cls; $P$ : 0.00; Q-Value: 0.6 ; $p$ value: 0.73 ; Egger's $p$ value: 0.21 ; Begg's $p$ value: 0.21 ), patients infected with cagA-positive strains are susceptible to DLBCL (Fig. 2). We found that there was a significant inverse association between infection with VacA-expressing H. pylori strains and gastric MALT lymphoma (OR: $0.92 ; 0.57-1.50$ with $95 \%$ Cl; $P$ : 32.3 ; Q-Value: $7.39 ; p$ value: 0.1 ; Egger's $p$ value: 0.79 ; Begg's $p$ value: 0.45 ). We also observed a strong association between $\operatorname{cag} A$ status and the development of DLBCL, indicating the importance of this virulence factor in the immune-pathogenesis of gastric MALT lymphoma. However, further investigation is required to confirm the results of this study.

\subsection{Publication bias analysis}

In the present study, the presence of bias in publication was evaluated using Begg's $p$ value and Egger's $p$ value. We did not observe any significant publication bias in the present study, although the funnel plot showed a slight publication bias in the eligible studies (Fig. 3).

\section{Discussion}

As mentioned, MALT lymphoma and diffuse large B-cell lymphoma are as both indolent and aggressive features of PLG, respectively. Mucosal and non-mucosal organs in human body normally lack lymphocytes, and infiltration of B-cell lymphocytes occurs as a result of chronic inflammation or autoimmune diseases (particularly Hashimoto's thyroiditis). Gastric MALT lymphoma is the most common marginal zone lymphoma $[20,46,47]$. Today, the role of $H$. pylori infection in the development of gastric MALT lymphoma has been well-described, and recent studies have shown that eradication infection in extranodal marginal zone B-cell lymphoma can lead to lymphoma regression in $60-90 \%$ of cases [48]. The most likely hypothesis is that persistent infection with $\mathrm{H}$. pylori can lead to inflammation and infiltration of lymphocytes into the stomach with persistent stimulation of the immune response, and active proliferation of B cells leads to the formation of lymph follicles and the onset of gastric MALT lymphoma [49]. To date, several studies have attempted to investigate the association between cagA status and the development of gastric MALT lymphoma, but the results are unclear [34, 36, 37]. In addition, no comprehensive meta-analysis has been performed in this area; therefore, using the available 
evidence, we conducted the present meta-analysis to evaluate the exact role of the CagA antigen in the development of gastric MALT lymphoma.

Overall, we did not find a meaningful relationship between cagA status and gastric MALT lymphoma in Western countries. Interestingly, the present analysis showed an inverse association between cagA status and gastric MALT lymphoma risk in the Asian population (OR: $0.104 ; 0.036-0.307$ with $95 \% \mathrm{Cls}$ ).

Previous studies indicated that early lymphomagenesis in lymphomas is a process related to CD4 + T cells stimulated by $H$. pylori antigens, and the proliferation of B-cell gastric lymphoma is dependent on CD40-mediated signaling, Th2 activities, co-stimulatory CD80, and CD86 [27, 50-53]. Hussel et al. (1993) in their studies showed that the reduction of infiltrating T cells can significantly disrupt the effect of $H$. pylori infection on tumor B-cell proliferation [54]. Umehara et al. found that CagA could inhibit B-lymphoid cell proliferation by IL-3-dependent signaling by targeting the JAK-STAT pathway [29]. Liu et al. (2001) showed that the API2-MALT1 chimeric transcript was observed in all cases of $H$. pylori-infected gastric MALT lymphoma [55]. However, there is no correlation between $H$. pylori infection and the presence of API2-MALT1 [56]. In general, the formation of gastric MALT lymphoma is based on the dependent and independent mechanisms of $H$. pylori infection; in $H$. pylori-dependent manner (in most cases), phosphorylated CagA inhibits p53 accumulation, whereas, in H. pylori-independent state, genetic aberrations leadto nuclear translocation of API2-MALT1 chimeric transcript and BCL10, and eventually gastric MALT lymphoma [29, 57].

Ohnishi et al. (2008) demonstrated the major role of CagA in the development of gastric and hematologic neoplasms [58]. After transfer to B-cell lymphocytes via the type 4 secretory system (T4SS), CagA, through the formation of phosphorylated CagA-SHP-2 complex by affecting ERK1, ERK2, p38MAPKs, $\mathrm{BCL2}$, and NF-KB, as well suppression of $\mathrm{p} 53$ accumulation or inhibition of the JAK-STAT signaling pathway, promotes lymphogenesis and immortalization of B-cell lymphocytes [29, 49, 59]. Evaluation of cagA status in patients with extranodal marginal zone B-cell lymphoma and DLBCL showed that this gene significantly increases the risk of developing DLBCL (OR: 6.43; $2.45-16.84$ with 95\% Cls). Based on previous studies, the presence of cagA-positive $H$. pylori strains in patients with DLBCL is significantly higher than that in patients with extranodal marginal zone B-cell lymphoma [34]. Unfortunately, no studies have yet examined the relationship between CagA and VacA in the development of gastric MALT lymphoma, but VacA induces apoptosis by forming a vacuole and release of cytochrome $c$ from mitochondria and appears to inhibit the development of gastric MALT lymphoma [60,61]. The role of VacA in gastric MALT lymphoma is also controversial, and in one study, Miehlke et al. (1998) showed that the level of the vacA $1 \mathrm{~m} 1$ genotype in gastric MALT lymphoma patients is high; however, Doorn et al. (1999) rejected this hypothesis $[39,62]$. Although we could not assess the correlation between cagA and vacA, we observed an inverse association between the vacA genotype and gastric MALT lymphoma (OR: $0.92 ; 0.57-1.50$ with $95 \% \mathrm{Cls}$ ). Although vacA is a potent immune gene, given the fact that this protein causes apoptosis, it does not appear to play a significant role in the development of gastric MALT lymphoma $[63,64]$. In general, the most likely hypothesis to describe the role of $H$. pylori in the development of gastric MALT lymphoma is that this bacterium (CagA-dependent or independent) causes 
chronic gastritis, resulting in the production of IL-8 and other molecules associated with neutrophil chemotaxis. Neutrophil activation leads to destruction of the gastric mucosa and close contact of CD4+ T cells with $H$. pylori, where the activity of DC and CD4 $+\mathrm{T}$ cells causes $\mathrm{B}$ cells to mature. Continuous stimulation and proliferation of B-cell lymphocytes leads to the formation of lymph follicles, in which case the patient with PGL develops to DLBCL. In other words, no H. pylori eradication, particularly cagApositive strains, leads to the translocation of CagA into B cells. Intracellular CagA causes DNA and microRNA damage by reactive oxygen and nitrogen species (RONS), inhibition of p53, and chromosomal translocation, and ultimately the development of DLBCL (Fig. 4).

Our study had several limitations including: I) low sample size, II) evaluation of only English studies, III) high heterogeneity in some cases, IV) inaccessibility to the raw data to find out EPIYA motifs CagA, as well as correlation between CagA and VacA, V) the lack of a sensitivity analysis. The results of the study are unstable under the influence of significant heterogeneity, and more research is needed to confirm the current findings.

\section{Conclusion}

According to the recent literature, PGL ranges from MALT lymphoma to DLBCL. In the present study, we performed a large pooled analysis to evaluate the role of $c a g A$ status in the pathogenesis of the gastric MALT lymphoma. Overall, based on our results, no association was found between cagA status and the development of MALT lymphoma. Nevertheless, CagA can stimulate lymphogenesis and leads to the contentious proliferation and immortalization of B cells; therefore, it plays an important role in the development of DLBCL of the stomach.

\section{Abbreviations}

Helicobacter pylori (H. pylori)

Primary gastric lymphoma (PGL)

Mucosa-associated lymphoid tissue (MALT)

Cytotoxin-associated gene A (CagA)

Polymerase chain reaction (PCR)

Pathogenicity islands (PAls)

Interleukin 8 (IL-8)

Cell-mediated immunity (CMI)

Confidence intervals (Cls) 
Odds ratio (OR)

Reactive oxygen species (ROS)

Reactive oxygen and nitrogen species (RONS)

Non-ulcer dyspepsia (NUD)

Newcastle-Ottawa scale (NOS)

\section{Declarations}

\section{Ethics approval and consent to participate}

Not applicable.

\section{Consent for publication}

Not applicable.

\section{Availability of data and materials}

All data generated or analyzed during this study are included in this published article and its supplementary information files

\section{Competing interests}

The authors declare that they have no competing interests.

\section{Funding}

Not applicable.

\section{Authors' Contributions}

MK1 and AS equally contributed to the conception and design of the study.

MK1 and MK2 performed the literature review and analysis.

All authors equally contributed to drafting, critical revision, editing, and final approval.

\section{Acknowledgements}

We appreciate from all Mashhad University of Medical Sciences, Jiroft University of Medical Sciences, and Oita University Faculty of Medicine, Yufu, Japan. 


\section{References}

1. Kusters JG, Van Vliet AH, Kuipers EJ: Pathogenesis of Helicobacter pylori infection. Clinical microbiology reviews 2006, 19(3):449-490.

2. De Falco M, Lucariello A, laquinto S, Esposito V, Guerra G, De Luca A: Molecular mechanisms of Helicobacter pylori pathogenesis. Journal of cellular physiology 2015, 230(8):1702-1707.

3. Youssefi M, Tafaghodi M, Farsiani H, Ghazvini K, Keikha M: Helicobacter pylori infection and autoimmune diseases, Is there an association with systemic lupus erythematosus, rheumatoid arthritis, autoimmune atrophy gastritis and autoimmune pancreatitis? A systematic review and metaanalysis study. Journal of Microbiology, Immunology and Infection 2020.

4. Hooi JK, Lai WY, Ng WK, Suen MM, Underwood FE, Tanyingoh D, Malfertheiner P, Graham DY, Wong VW, Wu JC: Global prevalence of Helicobacter pylori infection: systematic review and meta-analysis. Gastroenterology 2017, 153(2):420-429.

5. Karbalaei M, Keikha M: Potential association between the hopQ alleles of Helicobacter pylori and gastrointestinal diseases: A systematic review and meta-analysis. Meta Gene 2020:100816.

6. Šterbenc A, Jarc E, Poljak M, Homan M: Helicobacter pylori virulence genes. World journal of gastroenterology 2019, 25(33):4870.

7. Servetas SL, Kim A, Su H, Cha JH, Merrell DS: Comparative analysis of the Hom family of outer membrane proteins in isolates from two geographically distinct regions: the United States and South Korea. Helicobacter 2018, 23(2):e12461.

8. Gressmann H, Linz B, Ghai R, Pleissner K-P, Schlapbach R, Yamaoka Y, Kraft C, Suerbaum S, Meyer $T F$, Achtman M: Gain and loss of multiple genes during the evolution of Helicobacter pylori. PLOS Genet 2005, 1(4):e43.

9. Keikha M, Karbalaei M: EPIYA motifs of Helicobacter pylori cagA genotypes and gastrointestinal diseases in the Iranian population: a systematic review and meta-analysis. New Microbes and New Infections 2021:100865.

10. Higashi H, Tsutsumi R, Fujita A, Yamazaki S, Asaka M, Azuma T, Hatakeyama M: Biological activity of the Helicobacter pylori virulence factor CagA is determined by variation in the tyrosine phosphorylation sites. Proceedings of the National Academy of Sciences 2002, 99(22):14428-14433.

11. Lind J, Backert S, Hoffmann R, Eichler J, Yamaoka Y, Perez-Perez GI, Torres J, Sticht H, Tegtmeyer N: Systematic analysis of phosphotyrosine antibodies recognizing single phosphorylated EPIYA-motifs in CagA of East Asian-type Helicobacter pylori strains. BMC microbiology 2016, 16(1):201.

12. Li Q, Liu J, Gong Y, Yuan Y: Association of CagA EPIYA-D or EPIYA-C phosphorylation sites with peptic ulcer and gastric cancer risks: A meta-analysis. Medicine 2017, 96(17).

13. Yamaoka Y: Mechanisms of disease: Helicobacter pylori virulence factors. Nature reviews Gastroenterology \& hepatology 2010, 7(11):629.

14. Matsunari O, Shiota S, Suzuki R, Watada M, Kinjo N, Murakami K, Fujioka T, Kinjo F, Yamaoka Y: Association between Helicobacter pylori virulence factors and gastroduodenal diseases in Okinawa, 
Japan. Journal of clinical microbiology 2012, 50(3):876-883.

15. Crabtree J, Xiang Z, Lindley I, Tompkins D, Rappuoli R, Covacci A: Induction of interleukin-8 secretion from gastric epithelial cells by a cagA negative isogenic mutant of Helicobacter pylori. Journal of clinical pathology 1995, 48(10):967-969.

16. Crabtree J, Covacci A, Farmery S, Xiang Z, Tompkins D, Perry S, Lindley I, Rappuoli R: Helicobacter pylori induced interleukin-8 expression in gastric epithelial cells is associated with CagA positive phenotype. Journal of clinical pathology 1995, 48(1):41-45.

17. Machado AMD, Figueiredo C, Touati E, Maximo V, Sousa S, Michel V, Carneiro F, Nielsen FC, Seruca R, Rasmussen LJ: Helicobacter pylori infection induces genetic instability of nuclear and mitochondrial DNA in gastric cells. Clinical Cancer Research 2009, 15(9):2995-3002.

18. Karbalaei M, Khorshidi M, Sisakht-pour B, Ghazvini K, Farsiani H, Youssefi M, Keikha M: What are the effects of IL-1 $\beta$ (rs1143634), IL-17A promoter (rs2275913) and TLR4 (rs4986790) gene polymorphism on the outcomes of infection with $\mathrm{H}$. pylori within as Iranian population, A systematic review and meta-analysis. Gene Reports 2020:100735.

19. Isaacson P, Wright DH: Malignant lymphoma of mucosa-associated lymphoid tissue. A distinctive type of B-cell lymphoma. Cancer 1983, 52(8):1410-1416.

20. Filip PV, Cuciureanu D, Diaconu LS, Vladareanu AM, Pop CS: MALT lymphoma: epidemiology, clinical diagnosis and treatment. Journal of Medicine and Life 2018, 11(3):187.

21. Nakamura S, Matsumoto T: Helicobacter pylori and gastric mucosa-associated lymphoid tissue lymphoma: recent progress in pathogenesis and management. World Journal of Gastroenterology: WJG 2013, 19(45):8181.

22. Carlson SJ, Yokoo H, Vanagunas A: Progression of gastritis to monoclonal B-cell lymphoma with resolution and recurrence following eradication of Helicobacter pylori. Jama 1996, 275(12):937-939.

23. Bilgilier C, Simonitsch-Klupp I, Kiesewetter B, Raderer M, Dolak W, Makristathis A, Steininger C: Prevalence of clarithromycin-resistant Helicobacter pylori strains in gastric mucosa-associated lymphoid tissue lymphoma patients. Annals of hematology 2016, 95(7):1115-1120.

24. Asenjo L, Gisbert J: Prevalence of Helicobacter pylori infection in gastric MALT lymphoma: a sistematic review. Revista Española de Enfermedades Digestivas 2007, 99(7):398.

25. Wotherspoon AC, Diss T, Pan L, Isaacson P, Doglioni C, Moschini A, de Boni M: Regression of primary low-grade B-cell gastric lymphoma of mucosa-associated lymphoid tissue type after eradication of Helicobacter pylori. The Lancet 1993, 342(8871):575-577.

26. Greiner A, Knörr C, Qin Y, Sebald W, Schimpl A, Banchereau J, Müller-Hermelink H: Low-grade B cell lymphomas of mucosa-associated lymphoid tissue (MALT-type) require CD40-mediated signaling and Th2-type cytokines for in vitro growth and differentiation. The American journal of pathology 1997, 150(5):1583.

27. HUSSELL T, ISAACSON PG, CRABTREE JE, Spencer J: Helicobacter pylori-specific tumour-infiltrating $T$ cells provide contact dependent help for the growth of malignant $B$ cells in low-grade gastric lymphoma of mucosa-associated lymphoid tissue. The Journal of pathology 1996, 178(2):122-127. 
28. Lin W-C, Tsai H-F, Kuo S-H, Wu M-S, Lin C-W, Hsu P-I, Cheng A-L, Hsu P-N: Translocation of Helicobacter pylori CagA into Human B lymphocytes, the origin of mucosa-associated lymphoid tissue lymphoma. Cancer research 2010, 70(14):5740-5748.

29. Umehara S, Higashi H, Ohnishi N, Asaka M, Hatakeyama M: Effects of Helicobacter pylori CagA protein on the growth and survival of B lymphocytes, the origin of MALT lymphoma. Oncogene 2003, 22(51):8337-8342.

30. Chen CY, Wang FY, Wan HJ, Jin XX, Wei J, Wang ZK, Liu C, Lu H, Shi H, Li DH: Amino acid polymorphisms flanking the EPIYA-A motif of $\mathrm{H}$ elicobacter pylori CagA C-terminal region is associated with gastric cancer in $\mathbf{E}$ ast $\mathbf{C}$ hina: Experience from a single center. Journal of digestive diseases 2013, 14(7):358-365.

31. Krisch LM, Posselt G, Hammerl P, Wessler S: CagA phosphorylation in Helicobacter pylori-infected B cells is mediated by the nonreceptor tyrosine kinases of the Src and Abl families. Infection and immunity 2016, 84(9):2671-2680.

32. Peng JC, Zhong L, Ran ZH: Primary lymphomas in the gastrointestinal tract. Journal of digestive diseases 2015, 16(4):169-176.

33. Wang H-P, Zhu Y-L, Shao W: Role of Helicobacter pylori virulence factor cytotoxin-associated gene A in gastric mucosa-associated lymphoid tissue lymphoma. World journal of gastroenterology: WJG 2013, 19(45):8219.

34. Eck M, Schmausser B, Haas R, Greiner A, Czub S, Muller-Hermelink H: MALT-type lymphoma of the stomach is associated with Helicobacter pylori strains expressing the CagA protein. Gastroenterology 1997, 112(5):1482-1486.

35. Askari P, Karbalaei M, Ghazvini K, Keikha M: Severe clinical outcomes of infection with babA2positive Helicobacter pylori strains in the Iranian population: A systematic review and meta-analysis. Meta Gene 2021:100911.

36. De Jong D, Van Der Hulst RW, Pals G, Van Dijk WC, Van Der Ende A, Tytgat GN, Taal BG, Boot H: Gastric non-Hodgkin lymphomas of mucosa-associated lymphoid tissue are not associated with more aggressive Helicobacter pylori strains as identified by CagA. American journal of clinical pathology 1996, 106(5):670-675.

37. Peng H, Ranaldi R, Diss TC, Isaacson PG, Bearzi I, Pan L: High frequency of CagA+ Helicobacter pylori infection in high-grade gastric MALT B-cell lymphomas. The Journal of Pathology: A Journal of the Pathological Society of Great Britain and Ireland 1998, 185(4):409-412.

38. Lamarque D, Gilbert T, Roudot-Thoraval F, Deforges L, Chaumette MT, Delchier JC: Seroprevalence of eight Helicobacter pylori antigens among 182 patients with peptic ulcer, MALT gastric lymphoma or non-ulcer dyspepsia. Higher rate of seroreactivity against CagA and 35-kDa antigens in patients with peptic ulcer originating from Europe and Africa. European journal of gastroenterology \& hepatology 1999, 11(7):721-726.

39. van Doorn NE, Namavar F, van Doorn L-J, Durrani Z, Kuipers EJ, Vandenbroucke-Grauls CM: Analysis of vacA, cagA, and IS605 Genotypes and Those Determined by PCR Amplification of DNA between 
Repetitive Sequences of Helicobacter pyloriStrains Isolated from Patients with Nonulcer Dyspepsia or Mucosa-Associated Lymphoid Tissue Lymphoma. Journal of clinical microbiology 1999, 37(7):2348-2349.

40. Schmaußer B, Eck M, Greiner A, Kraus M, Müller-Hermelink HK: Mucosal humoral immune response to CagA shows a high prevalence in patients with gastric MALT-type lymphoma. Virchows Archiv 2000, 436(2):115-118.

41. Delchier J-C, Lamarque D, Levy M, Tkoub EM, Copie-Bergman C, Deforges L, Chaumette M-T, Haioun C: Helicobacter pylori and gastric lymphoma: high seroprevalence of CagA in diffuse large B-cell lymphoma but not in low-grade lymphoma of mucosa-associated lymphoid tissue type. The American journal of gastroenterology 2001, 96(8):2324-2328.

42. Koehler C, Mues M, Dienes H, Kriegsmann J, Schirmacher P, Odenthal M: Helicobacter pylori genotyping in gastric adenocarcinoma and MALT lymphoma by multiplex PCR analyses of paraffin wax embedded tissues. Molecular Pathology 2003, 56(1):36.

43. Lehours $P$, Zheng $Z$, Skoglund A, Mégraud F, Engstrand $L$ : Is there a link between the lipopolysaccharide of Helicobacter pylori gastric MALT lymphoma associated strains and lymphoma pathogenesis? PLoS One 2009, 4(10):e7297.

44. Abadi ATB, Ghasemzadeh A, Mobarez AM: Low frequency of cagA-positive Helicobacter pylori strains isolated from Iranian patients with MALT lymphoma. Internal and emergency medicine 2013, 8(1):49-53.

45. Hashinaga M, Suzuki R, Akada J, Matsumoto T, Kido Y, Okimoto T, Kodama M, Murakami K, Yamaoka Y: Differences in amino acid frequency in CagA and VacA sequences of Helicobacter pylori distinguish gastric cancer from gastric MALT lymphoma. Gut pathogens 2016, 8(1):54.

46. Ye H, Liu H, Attygalle A, Wotherspoon AC, Nicholson AG, Charlotte Fdr, Leblond V, Speight P, Goodlad $\mathrm{J}$, Lavergne-Slove A: Variable frequencies of $\mathrm{t}(11,18)(q 21, q 21)$ in MALT lymphomas of different sites: significant association with CagA strains of $\mathrm{H}$ pylori in gastric MALT lymphoma. Blood 2003, 102(3):1012-1018.

47. Keikha M, Karbalaei M: Correlation between the geographical origin of Helicobacter pylori homBpositive strains and their clinical outcomes: a systematic review and meta-analysis. $B M C$ gastroenterology 2021, 21(1):1-8.

48. Zucca E, Roggero E, Cavalli F: Helicobacter pylori eradication in gastric: mucosa-associated lymphoid: tissue lymphomas. Annals of internal medicine 1996, 124(2):275-276.

49. Floch P, Mégraud F, Lehours P: Helicobacter pylori strains and gastric MALT lymphoma. Toxins 2017, 9(4):132.

50. Farinha P, Gascoyne RD: Helicobacter pylori and MALT lymphoma. Gastroenterology 2005, 128(6):1579-1605.

51. Hauer A, Finn T, MacDonald T, Spencer J, Isaacson P: Analysis of TH1 and TH2 cytokine production in low grade B cell gastric MALT-type lymphomas stimulated in vitro with Helicobacter pylori. Journal of clinical pathology 1997, 50(11):957-959. 
52. Knörr C, Amrehn C, Seeberger H, Rosenwald A, Stilgenbauer S, Ott G, Hermelink H-KM, Greiner A: Expression of costimulatory molecules in low-grade mucosa-associated lymphoid tissue-type lymphomas in vivo. The American journal of pathology 1999, 155(6):2019-2027.

53. Mueller A, O'Rourke J, Chu P, Chu A, Dixon MF, Bouley DM, Lee A, Falkow S: The role of antigenic drive and tumor-infiltrating accessory cells in the pathogenesis of helicobacter-induced mucosaassociated lymphoid tissue lymphoma. The American journal of pathology 2005, 167(3):797-812.

54. Hussell T, Isaacson PG, Spencer J, Crabtree J: The response of cells from low-grade B-cell gastric lymphomas of mucosa-associated lymphoid tissue to Helicobacter pylori. The Lancet 1993, 342(8871):571-574.

55. Liu H, Ruskon-Fourmestraux A, Lavergne-Slove A, Ye H, Molina T, Bouhnik Y, Hamoudi RA, Diss TC, Dogan A, Megraud F: Resistance of $t(11,18)$ positive gastric mucosa-associated lymphoid tissue lymphoma to Helicobacter pylori eradication therapy. The Lancet 2001, 357(9249):39-40.

56. Baens M, Maes B, Steyls A, Geboes K, Marynen P, De Wolf-Peeters C: The product of the $t(11,18)$, an API2-MLT fusion, marks nearly half of gastric MALT type lymphomas without large cell proliferation. The American journal of pathology 2000, 156(4):1433-1439.

57. Kuo S, Chen L, Lin C, Wu M, Hsu P, Tsai H, Chu C, Tzeng Y, Wang H, Yeh K: Detection of the Helicobacter pylori CagA protein in gastric mucosa-associated lymphoid tissue lymphoma cells: clinical and biological significance. Blood cancer journal 2013, 3(7):e125.

58. Ohnishi N, Yuasa H, Tanaka S, Sawa H, Miura M, Matsui A, Higashi H, Musashi M, Iwabuchi K, Suzuki $\mathrm{M}$ : Transgenic expression of Helicobacter pylori CagA induces gastrointestinal and hematopoietic neoplasms in mouse. Proceedings of the National Academy of Sciences 2008, 105(3):1003-1008.

59. Zhu Y, Wang C, Huang J, Ge Z, Dong Q, Zhong X, Su Y, Zheng S: The Helicobacter pylori virulence factor CagA promotes Erk1/2-mediated Bad phosphorylation in lymphocytes: a mechanism of CagAinhibited lymphocyte apoptosis. Cellular microbiology 2007, 9(4):952-961.

60. Matsumoto A, Isomoto H, Nakayama M, Hisatsune J, Nishi Y, Nakashima Y, Matsushima K, Kurazono H, Nakao K, Hirayama T: Helicobacter pylori VacA reduces the cellular expression of STAT3 and prosurvival Bcl-2 family proteins, Bcl-2 and Bcl-X L, leading to apoptosis in gastric epithelial cells. Digestive diseases and sciences 2011, 56(4):999-1006.

61. Palframan SL, Kwok T, Gabriel K: Vacuolating cytotoxin A (VacA), a key toxin for Helicobacter pylori pathogenesis. Frontiers in cellular and infection microbiology 2012, 2:92.

62. Miehlke S, Meining A, Morgner A, Bayerdörffer E, Lehn N, Stolte M, Graham DY, Go MF: Frequency of vacA genotypes and cytotoxin activity in Helicobacter pylori associated with low-grade gastric mucosa-associated lymphoid tissue lymphoma. Journal of clinical microbiology 1998, 36(8):23692370.

63. Ihan A, Pinchuk IV, Beswick EJ: Inflammation, Immunity, and Vaccines for H elicobacter pylori Infection. Helicobacter 2012, 17:16-21.

64. Cover TL, Krishna US, Israel DA, Peek RM: Induction of gastric epithelial cell apoptosis by Helicobacter pylori vacuolating cytotoxin. Cancer research 2003, 63(5):951-957. 

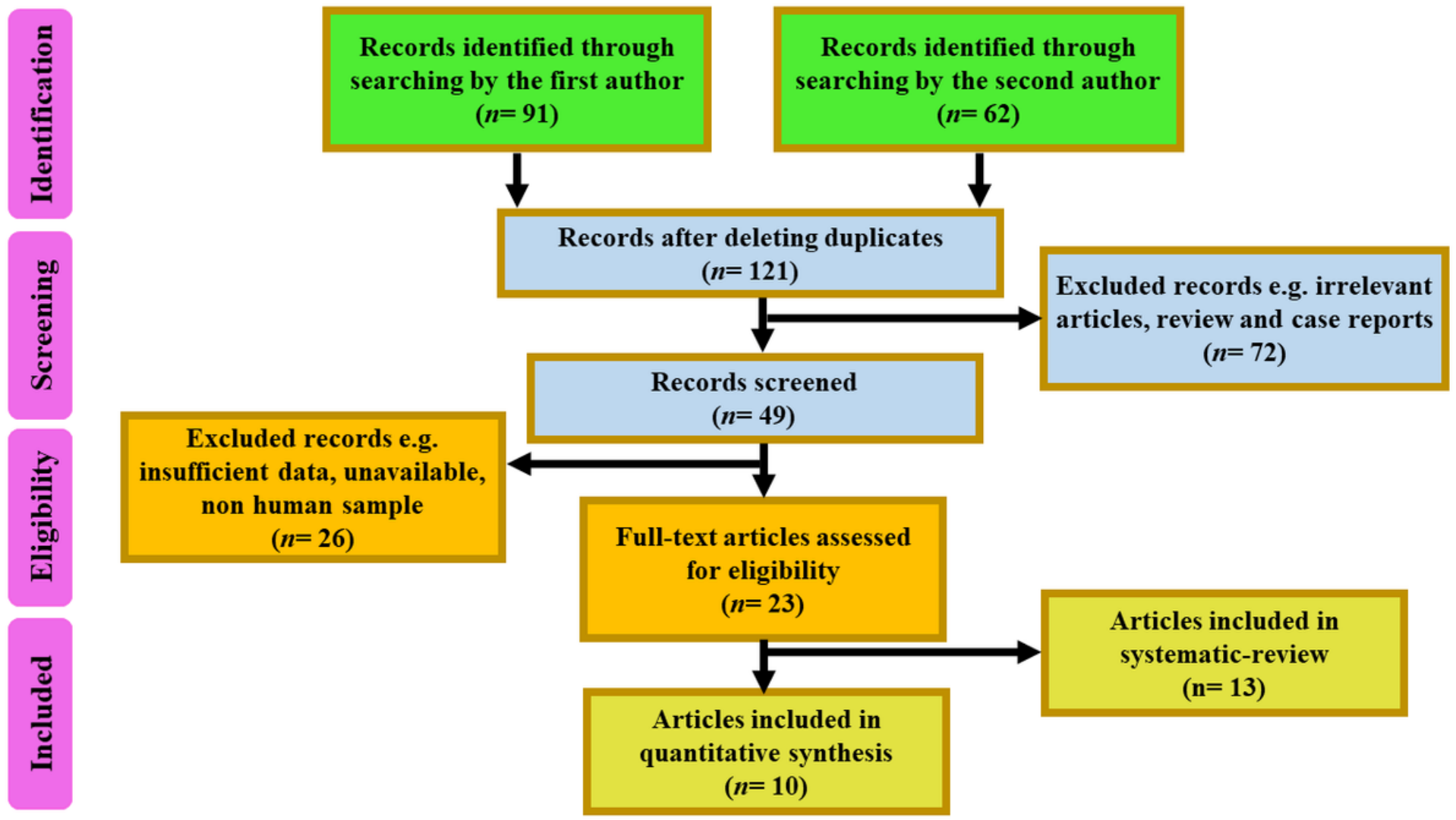

Figure 1

Flowchart of the article search strategy and study selection.

\begin{tabular}{|c|c|c|c|c|c|c|}
\hline \multirow{2}{*}{$\frac{\text { Group by }}{\text { Location }}$} & \multirow[t]{2}{*}{ Study name } & \multirow[b]{2}{*}{$\begin{array}{l}\text { Odds } \\
\text { ratio }\end{array}$} & \multicolumn{3}{|c|}{ Statistics for each study } & \multirow[b]{2}{*}{ p-Value } \\
\hline & & & $\begin{array}{r}\text { Lower } \\
\text { limit }\end{array}$ & $\begin{array}{l}\text { Upper } \\
\text { limit }\end{array}$ & Z-Value & \\
\hline Asia & Talebi et al., 2013 & 0.038 & 0.012 & 0.120 & -5.560 & 0.000 \\
\hline Asia & Hashinaga et al., 2016 & 102.778 & 5.073 & 2082.262 & 3.018 & 0.003 \\
\hline Asia & & 0.104 & 0.036 & 0.307 & -4.113 & 0.001 \\
\hline Western & Jong et al., 1996 & 0.754 & 0.202 & 2.817 & -0.420 & 0.675 \\
\hline Western & Peng et al., 1998 & 2.829 & 1.342 & 5.964 & 2.733 & 0.006 \\
\hline Western & Lamarque et al., 1999 & 2.429 & 0.798 & 7.394 & 1.563 & 0.118 \\
\hline Western & Doorn et al., 1999 & 0.357 & 0.086 & 1.482 & -1.418 & 0.156 \\
\hline Western & Schmaußer et al., 2000 & 0.286 & 0.026 & 3.146 & -1.023 & 0.306 \\
\hline Western & Delchier et al., 2001 & 1.593 & 0.734 & 3.457 & 1.178 & 0.239 \\
\hline Western & Koehler et al., 2003 & 0.741 & 0.254 & 2.162 & -0.549 & 0.583 \\
\hline Western & Lehours et al., 2009 & 0.854 & 0.352 & 2.072 & -0.349 & 0.727 \\
\hline Western & & 1.300 & 0.906 & 1.866 & 1.423 & 0.155 \\
\hline Overall & & 1.007 & 0.715 & 1.419 & 0.041 & 0.968 \\
\hline
\end{tabular}

Odds ratio and $95 \% \mathrm{CI}$

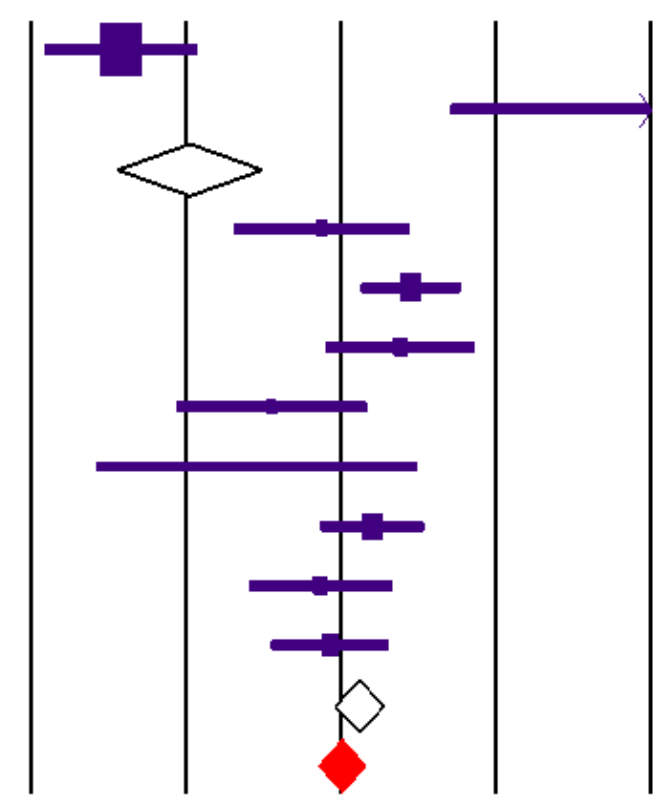


Figure 2

Forest plot of the meta-analysis on the potential association between cagA status and gastric MALT lymphoma with subgroup analysis based on the geographical origin of the studies.
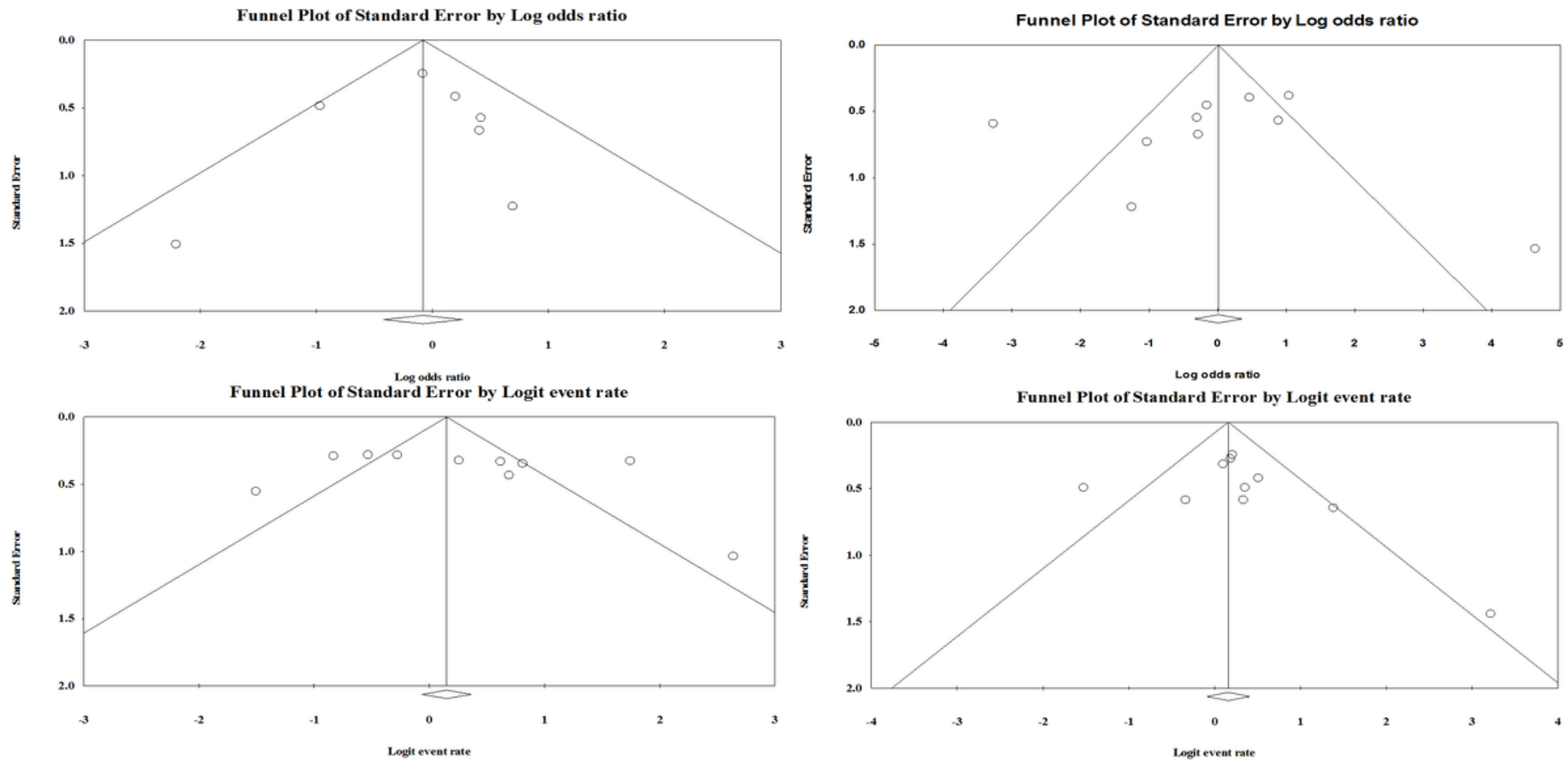

Figure 3

Funnel plot with 95\% Cls representative the effect sizes derived from each study (logit event rate) against their corresponding standard errors. 


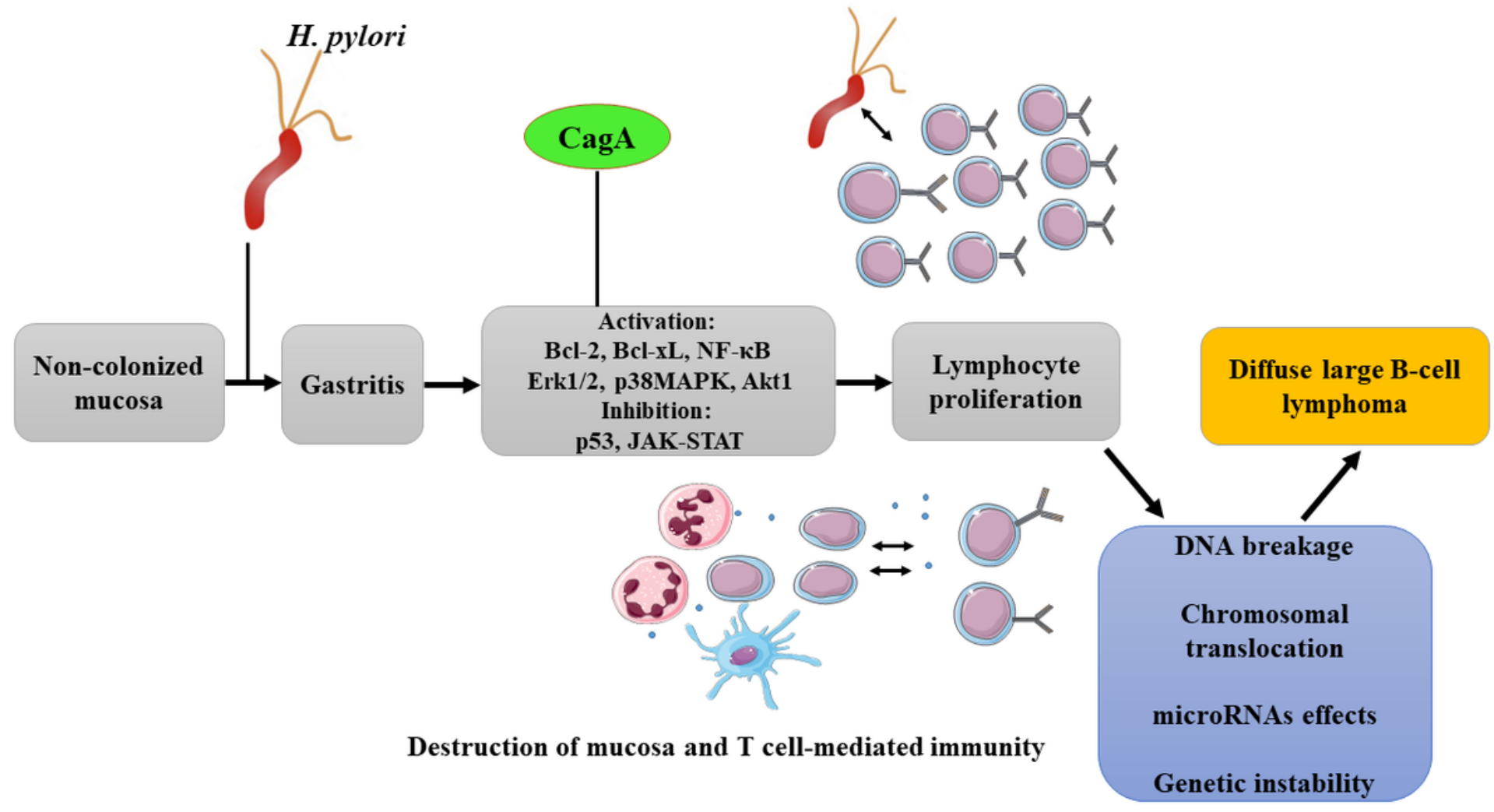

\section{Figure 4}

Colonization of the stomach with cagA-positive $\mathrm{H}$. pylori strains and progression to DLBCL. Following long-term colonization of the bacterium in stomach mucosa, CagA protein is secreted into cells via T4SS. Upon entrance of CagA, intracellular CagA-SHP-2 complex is formed. Although there is probably no association between the CagA and progression of PGL to MALT Iymphoma, this complex potentially stimulates the lymphogenesis process and ultimately DLBCL by activating on ERK1, ERK2, p38MAPKs, $\mathrm{BCL2}$, and NF-KB, as well as inhibiting p53 or the JAK-STAT signaling pathway. It also damages DNA and microRNA by producing reactive oxygen and nitrogen species (RONS). 